Reseña

\section{Guillermina del Valle Pavón. Donativos, préstamos y privilegios. Los mercaderes y mineros en la ciudad de México durante la guerra anglo-española de 1779-1783. México, Instituto Mora, 2016, 227 pp. ISBN: 9786078711102.}

Guillermina del Valle Pavón, autora del presente estudio, es profesora-investigadora del Instituto de Investigaciones Dr. José María Luis Mora; miembro del Sistema Nacional de Investigadores y directora editorial de América Latina en la Historia Económica. Posee una larga trayectoria investigadora como demuestran diversas publicaciones sobre las empresas de los mercaderes de la ciudad de México y el papel fiscal del Consulado en que se agrupaban. Con este bagaje, la autora presenta esta monografía desde su experiencia investigador, pero esta vez desde un punto de vista novedoso. Y es que, en efecto, se aborda el análisis del papel que los mercaderes novohispanos $\mathrm{y}$ hombres de negocios españoles representan, no en tiempos de paz, sino en el contexto de la guerra anglo-española de 1779-1783.

El objetivo principal de este trabajo es analizar los mecanismos por los que la corona española extraería grandes contribuciones extraordinarias, en forma de donativos y préstamos, aportados por los mercaderes novohispanos para fortalecer la Real Armada y financiar los gastos que ocasionaría el conflicto antes mencionado. Y aquí radica una de las principales novedades del libro, puesto que en relación con la obtención de recursos para el fortalecimiento de las fuerzas navales en la América hispana existe un vacío historiográfico. La tesis de la autora es que en Nueva España los principales contribuyentes de los recursos suplementarios demandados por el virrey fueron los mercaderes de la ciudad de México, mientras que los tribunales del Consulado y Minería operarían como intermediarios financieros del erario virreinal con el objeto de reunir empréstitos millonarios mediante la recepción de depósitos de individuos y corporaciones rentistas.

La periodización se subordina al análisis general y no resulta, en absoluto, una elección baladí, ya que, aunque en realidad el análisis parte de 1774 , fecha en que se autoriza el comercio de bienes locales entre las posesiones hispanoamericanas del Pacífico, el libro concluye a fines de 1783, tras la prohibición del tráfico de efectos de Europa y Asia y a raíz de la paz con Gran Bretaña, momento en que cesó la solicitud de caudales extraordinarios a Nueva España.

El trabajo comienza con una amplia introducción en la que el aspecto más destacado es la valoración de la historiografía precedente. Estas primeras páginas se convierten en un magnífico instrumento de ayuda a futuros investigadores y una puesta al día exhaustiva, minuciosa y de gran valor para contextualizar el trabajo y poder apreciar mejor su singularidad y la excelencia en la profundidad del análisis.
A lo largo de tres capítulos se abordan las cuestiones fundamentales. Ellos constituyen el corazón y el alma del libro y, en la lectura de sus páginas, vamos encontrando las respuestas a los objetivos previamente señalados. En el primer capítulo se examinan las dádivas que solicitó el ministro de Indias en Nueva España con el fin de fortalecer la Real Armada, así como para satisfacer las necesidades económicas de los príncipes de Asturias y reunir el donativo «universal» que solicitó Carlos III para el sostenimiento de la guerra. En este capítulo se desgranan las circunstancias que permitieron al virrey en 1776 extraer del Consulado una enorme suma para la construcción de navíos de guerra y cómo la generosidad de la universidad de mercaderes sirvió de ejemplo a otras corporaciones como el Arzobispado y los cabildos eclesiásticos bajo su jurisdicción, instituciones todas ellas suministradoras de donaciones considerables. Se cuantifican las sumas ofrecidas y las realmente entregadas; en algún caso, se especifica, además, la fecha de solicitud y la de remisión, la cuantía del donativo y su destino. Gracias a estos cuadros conocemos no solo el número de los donantes y las cantidades aportadas, sino también sus nombres, tanto los de los mercaderes matriculados en el Consulado en 1781, como los de los relacionados con el comercio con China, así como sus aportaciones individuales.

En el segundo capítulo, dedicado al libre comercio por el Pacífico hispanoamericano, se analizan los negocios que realizaron entre 1774 y 1783 por el Mar del Sur los acaudalados mercaderes de origen vizcaíno, Francisco Ignacio de Yraeta e Isidro Antonio de Icaza. Se observa cómo el crecimiento que presentó el tráfico de cacao de Guayaquil tras la apertura del comercio pacífico en 1774 y su incremento durante la guerra dio lugar a la movilidad de los hermanos Icaza de Panamá a Guayaquil, Lima y la ciudad de México. Se estudian las relaciones que establecieron Yraeta e Icaza y sus respectivas familias; las redes de negocios que tejieron con otros comerciantes de México y Perú, así como la forma en que sus vínculos interpersonales con el virrey y otras autoridades facilitaron los negocios que realizaban. Se concluye que Yraeta y otros mercaderes que trataban en el Pacífico otorgaron al virrey suplementos gratuitos y depositaron en el Consulado capitales a réditos para reunir el empréstito destinado a sostener el combate contra los británicos con el propósito de que el virrey les autorizara a reexpedir a Perú los géneros asiáticos y europeos, y se demuestra cómo fueron beneficiados por el conflicto.

En el tercer y último capítulo, bajo el epígrafe de «Suplementos, empréstitos y contraprestaciones», se estudian los recursos extraordinarios que requirió el virrey a fin de sostener las campañas bélicas de los años 1782-83. Se examinan los canales institucionales a los que recurrió Martín de Mayorga, virrey de Nueva España entre 1779 y 1783, para recibir préstamos gratuitos de los mercaderes y otros vecinos acaudalados de la ciudad de México, así como de los comisionistas penin- 
sulares que se encontraban en la capital del virreinato y en el pueblo de Jalapa. Se analiza el papel que desempeñaron los tribunales del Consulado y de minería como intermediarios financieros del real erario para reunir dos empréstitos a réditos por un millón de pesos cada uno. Los cuerpos del Consulado y de Minería, sus miembros y otros empresarios, pactaron importantes privilegios y concesiones a cambio de contribuciones pecuniarias para la defensa del imperio. El capítulo finaliza indagando acerca de la constitución de un nuevo tipo de deuda pública mediante la recepción en la hacienda regia de los depósitos de capellanías, obras pías, mayorazgos y otras fundaciones, así como de capitales frescos. Este capítulo es, probablemente, uno de los mayores activos del libro, pues en él, Guillermina del Valle trasciende la descripción de los hechos históricos y económicos y se arriesga a una interpretación valorativa elaborando nuevas hipótesis de trabajo que sugieren una novedosa línea de investigación y, quizás, la publicación en un futuro de una monografía.

El libro se enriquece con un epígrafe de conclusiones. La autora presume de que la universidad de mercaderes operó como intermediario financiero del erario virreinal con el propósito de influir en las autoridades reales para que se restaurara el sistema de flotas que les aseguraba el privilegio del monopolio mercantil y para evitar que se hiciera extensivo a Nueva España el Reglamento de Comercio Libre en el virreinato. Cuando el virrey demandó al tribunal mercantil el empréstito para las urgencias de la guerra, los cónsules y sus allegados activaron las redes que tenían con personas y corporaciones religiosas las cuales solían invertir a réditos los capitales piadosos que administraban y formaban parte de su patrimonio. La universidad de mercaderes brindaba mucha confianza a los rentistas porque tenía los medios para garantizar el pago de réditos y el poder para exigir a la Corona la restitución de los capitales. En otras palabras, el monarca podría contar con el consentimiento de sus vasallos sin tener que recurrir a medidas coercitivas, aunque ello hiciera necesaria una permanente negociación y el otorgamiento de contraprestaciones en forma de privilegios.

Al final se enumeran las principales colecciones documentales, rastreadas en distintos archivos y bibliotecas nacionales, entre los que destaca el Archivo General de la Nación (México), el Archivo General de Indias, el Archivo General de Simancas, el Archivo Histórico de Hacienda, la Biblioteca Nacional de México, la Biblioteca Nacional de España y el Centro de Estudios de Historia de México. Este elenco es, de por sí, demostrativo de la enorme complejidad en la elaboración de un trabajo que pretende ser ambicioso desde el punto de vista de la investigación de élite y que no escatima esfuerzos en la búsqueda documental. Pero en ello reside también una de las mayores dificultades de la investigación, que la autora ha superado con creces. El exhaustivo listado alfabético de fuentes secundarias y actualizada bibliografía, que supera ampliamente el centenar de referencias, es prueba evidente del conocimiento que Guillermina del Valle tiene de la historiografía específica del tema estudiado. El lector agradece la elaboración de un índice analítico, geográfico y onomástico, así como de los cuadros y de los mapas que encontramos a lo largo de las páginas del trabajo.

María Elisa Martínez Vega Universidad Complutense de Madrid

https://doi.org/10.33231/j.ihe.2020.03.007 